\title{
Servant Leadership dan Kompetensi Komunikasi:Dampaknya terhadap Kepuasan dan Kinerja Pendamping Program Keluarga Harapan (PKH) di Aceh Utara
}

\author{
Muhammad Sahem ${ }^{1}$, Ichsan ${ }^{2 *}$, Naufal Bachri ${ }^{3}$ \\ ${ }^{123}$ Program Pasca Sarjana Ilmu Manajemen Universitas Malikussaleh Lhokseumawe \\ Email : : sahem.kasem@gmail.com ${ }^{1}$, ichsan@unimal.ac.id ${ }^{2}$, naufal.bachri@ unimal.ac.id ${ }^{3}$
}

\begin{abstract}
This study aims to analyze the influence of servant leadership and communication competence on the performance of Conditional Cash TransfersCoordinatorsin North Aceh with job satisfaction as an intervening variable. This study uses primary data with a total sample of 150 respondents. The sampling method used is the census method. The data analysis model used is SEM-AMOS. The results show that servant leadership does not affect job satisfaction and performance. Communication competence has a significant effect on job satisfaction and performance. Job satisfaction has a significant effect on performance. Job satisfaction does not mediate the effect of servant leadership on performance. Meanwhile, job satisfaction mediates the effect of communication competence on performance. The implications of this research is that Conditional Cash TransfersCoordinatorsin North Aceh should be able to improve the communication competency because it has the greatest influence on the Conditional Cash Transfers Coordinators performance in North Aceh Regency.

Keywords: servant leadership, communication competence, job satisfaction, employeeperformance
\end{abstract}

\section{Pendahuluan}

Kemiskinan merupakan fenomena yang jelas terlihat di Indonesia dan menjadi salah satu akar permasalahan sosial yang multidimensi ditandai dengan pengangguran, keterbelakangan dan ketidakberdayaan masyarakat (Hermawati, 2012). Mengingat kemiskinan merupakan masalah sosial mendasar, maka pemerintah melalui Kementerian Sosial melaksanakan Program Keluarga Harapan (PKH) yang dalam istilah internasional dikenal dengan Conditional Cash Transfers (CCT). Program PKH merupakan program pemberian bantuan sosial bersyarat kepada keluarga miskin. Keberhasilan Program PKH sangat ditentukan oleh kinerja pendamping $\mathrm{PKH}$ dalam memberikan pendampingan kepada penerima bantuan PKH secara intensif dan berkelanjutan.

Kinerja pendamping PKH ditinjau dari aspek kualitas masih terdapat hal-hal yang perlu ditingkatkan lagi terutama berhubungan dengan kualitas validasi dan pemutakhiran data penerima bantuan PKH. Ketepatan waktu juga harus menjadi perhatian dari pendamping PKH karena tenggang waktu yang diberikan oleh pihak Kementerian Sosial dalam Sahem, Ichsan, Naufal Bachri 
menyelesaikan pekerjaan relatif singkat dengan berbagai kendala teknis di lapangan yang meliputi daerah-daerah yang sulit dijangkau dan tidak lengkapnya syarat-syarat administrasi. Aplikasi e-PKH sering mengalami overload yang disebabkan oleh pemutakhiran data dilakukan secara nasional juga dapat menyebabkan pendamping $\mathrm{PKH}$ mengalami keterlambatan dalam menyelesaikan pekerjaan. Selain itu, ketidakefektifan penempatan pendamping di tingkat kecamatan, sekalipun di kecamatan tersebut ada kebutuhan terhadap pendamping PKH. Kemandirian juga menjadi kendala, dengan indikasi masih ada pendamping PKH yang meminta bantuan pendamping PKH lain untuk menyelesaikan pekerjaan yang menjadi tanggung-jawabnya. Di samping kemandirian, rasa percaya diri juga penting karena masih ada pendamping PKH yang belum memiliki rasa percaya diri dalam berkomunikasi dengan penerima bantuan $\mathrm{PKH}$ dalam agenda rapat bulanan.

Di samping itu, keberhasilan program PKH juga sangat ditentukan oleh peran aktif pimpinan dalam mengarahkan pendamping PKH. Konsep servant leadership merupakan pendekatan kepemimpinan yang paling humanis dan realistis karena inti dari servant leadership adalah memberikan pelayanan. Kepemimpinan yang umum terjadi adalah sikap pemimpin yang menganggap bawahannya hanya sebagai alat untuk mencapai tujuan dan tidak memperlakukan bawahannya sebagai orang yang memiliki kebutuhan, keinginan dan kehendak. Persoalan lain terkait dengan kepemimpinan adalah masalah pemberdayaan, berupa masukan dan saran mengenai kendala-kendala yang dihadapi oleh pendamping PKH di lapangan belum sepenuhnya dapat diselesaikan dengan baik, seperti pekerjaan dengan batas waktu yang relatif singkat supaya pimpinan mengambil inisiatif untuk mengkomunikasikan secepatnya agar dapat diselesaikan secara tepat waktu.

Di samping servant leadership, kompetensi komunikasi juga berpengaruh signifikan terhadap kinerja karyawan (Akhyar, 2018). Kompetensi komunikasi memegang peranan penting dalam proses pendampingan program PKH karena salah satu tugas pendamping PKH adalah memberikan penyuluhan sosial. Pengetahuan komunikasi dapat diidentifikasikan salah satunya dari kemampuan pendamping PKH dalam menyampaikan informasi terkait dengan Program PKH. Pendamping selain mempunyai pengetahuan tentang PKH, juga dituntut untuk mempunyai pengetahuan dan wawasan yang luas terkait dengan kesehatan, pendidikan, kesejahteraan sosial dan pemberdayaan masyarakat. Permasalahan yang terjadi adalah masih ada pendamping PKH yang kurang dapat menguasai materi terkait dengan PKH. Menyangkut motivasi komunikasi 
permasalahannya adalah instruksi-instruksi yang disampaikan oleh pendamping PKH belum sepenuhnya mampu menggerakkan perubahan perilaku penerima bantuan $\mathrm{PKH}$ kearah yang lebih baik. Dalam hal keterampilan komunikasi, permasalahannya adalah masih ada pendamping PKH yang memiliki keterampilan kurang memadai dalam berkomunikasi ditandai dengan pola komunikasi pendamping dengan penerima bantuan PKH dalam rapat rutin bulanan masih satu arah, kurang tenang dalam menyampaikan informasi dan respon penerima bantuan PKH kurang antusias terhadap informasi yang disampaikan.

Kepuasan kerja merupakan evaluasi yang menggambarkan seseorang atas perasaan sikapnya senang atau tidak senang, puas atau tidak puas dalam bekerja (Rivai, 2009). Luthans (2009) mengatakan bahwa kepuasan kerja dapat dilihat dari aspek pembayaran, pekerjaan itu sendiri, rekan kerja, promosi dan kepenyeliaan. Dana sharing sebesar 5 persen dari total anggaran yang wajib dikeluarkan oleh pemerintah daerah belum dapat direalisasikan hingga tahun 2019. Selain itu, hubungan kerja yang kurang mendukung dalam membangun hubungan yang harmonis belum terlaksana dengan baik. Sikap tersebut berupa persaingan antar pendamping $\mathrm{PKH}$ dalam merebut simpati pimpinan dengan harapan pimpinan akan selalu memberikan perhatian terhadap pendamping tersebut. Kepuasan kerja yang berhubungan dengan pekerjaan terkait dengan peralatan kerja yang disediakan oleh instansi. Selama ini peralatan kerja yang disediakan masih kurang sebanding dengan jumlah pendamping $\mathrm{PKH}$ dan penggunaan software yang sering berubah-ubah juga membutuhkan waktu bagi pendamping PKH untuk menguasai software tersebut. Selanjutnya, pemberian rekomendasi untuk promosi jabatan bukan hanya sematamata berdasarkan kinerja akan tetapi juga mempertimbangkan aspek senioritas. Di samping itu, juga terdapat permasalahan terkait dengan kepenyeliaan. Hal ini karena pengawasan yang dilakukan belum dapat mencegah dan meminimalisir kesalahan kerja akan tetapi lebih kepada koreksi dan pemberian sanksi terhadap kesalahan tersebut.

Dari uraian latar belakang penelitian di atas, penelitian bertujuan untuk mengetahui pengaruh servant leardership, kompetensi komunikasi terhadap kinerja pendamping PKH di Aceh Utara, serta bagaimana peran kepuasan pendamping memediasi hubungannya.

\section{Kajian Pustaka}

\section{Kepemimpinan Melayani (Servant Leadership)}

Barbuto dan Wheeler (2006) mengatakan servant leadership sebagai suatu gaya kepemimpinan yang berawal dari perasaan yang tulus yang timbul dari hati yang Sahem, Ichsan, Naufal Bachri 
berkehendak untuk melayani, dimana kepemimpinan ini menempatkan kebutuhan karyawan sebagai prioritas utama dan memperlakukan karyawan sebagai rekan kerja, sehingga kedekatan diantara pemimpin dan karyawan sangat erat karena terlibat satu sama lain. Servant leadership merupakan kepemimpinan yang mendayaguna, mengembangkan, menjaga dan memelihara sehingga berkesinambungan untuk menciptakan rekan kerja yang menganut prinsip hubungan kerja sama yang solid dan bertanggung jawab. Dennis (2004) menyatakan bahwa servant leadership dapat diukur berdasarkan Servant Leadership Assement Instrument (SLAI) yang terdiri dari indikator kasih sayang, pemberdayaan, visi, kerendahan hati dan kepercayaan.

\section{Kompetensi Komunikasi}

Payne (2005) mendefinisikan kompetensi komunikasi sebagai kemampuan seorang individu untuk beradaptasi dan berkomunikasi secara efektif dalam segala situasi sosial sepanjang waktu. Kompetensi komunikasi dapat diukur dengan menggunakan aspek pengetahuan komunikasi,motivasi komunikasi dan keterampilan komunikasi. Keterampilan komunikasi dalam penelitian ini diukur dari otherorientation skill, sosial anxiety skill, expressiveness skill dan interaction management skill.

\section{Kepuasan Kerja}

Bachri (2018) menjelasakan bahwa kepuasan merupakan strategi manajerial dalam meningkatkan interaksi dalam proses organisasi. Robbins dan Judge (2015) menyatakan bahwa karyawan akan merasa puas bila tidak ada perbedaan antara yang diinginkan dengan persepsinya terhadap kenyataan. Ukuran kepuasan didasarkan pada kenyataan yang dihadapi dan diterima sebagai kompensasi usaha dan tenaga yang diberikan. Kepuasan kerja tergantung dari keseimbangan antara yang diharapkan dengan kenyataan. Bachri (2018) menjelaskan bahwa kepuasan adalah suatu ukuran keberhasilan organisasi dalam melayani karyawan. Luthans (2009) mengatakan bahwa indikator-indikator kepuasan kerja terdiri dari indikator kepuasan kerja dengan pembayaran, kepuasan kerja dengan pekerjaan, kepuasan kerja dengan rekan kerja, kepuasan kerja dengan promosi pekerjaan dan kepuasan kerja dengan kepenyeliaan.

\section{Kinerja Karyawan}

Mangkunegara (2010) mendefinisikan kinerja karyawan sebagai hasil kerja baik secara kualitas maupun secara kuantitas yang dicapai oleh karyawan dalam melaksanakan tugasnya sesuai dengan tanggung jawab yang diberikan kepadanya. Lubis dan Bachri 
(2015) mengatakan bahwa kinerja merupakan elemen keberhasilan suatu organisasi yang dapat dilihat dari sisi keuangan dan operasional. Bernardin dan Russel (2010) menyatakan bahwa indikator-indikator yang digunakan untuk mengukur kinerja karyawan adalah kualitas, kuantitas, ketepatan waktu, efektivitas biaya, kemandirian dan percaya diri.

\section{Kerangka Konseptual}

Harwiki (2013) menyatakan bahwa adanya pengaruh signifikan antara servant leadership terhadap kinerja karyawan. Sementara Lisbijanto (2014) menyatakan melalui kepuasan kerja ditemukan pengaruh tidak langsung antara servant leadership dengan kinerja. Artinya semakin tinggi kualitas penerapan servant leadership maka akan semakin tinggi pula tingkat kinerja karyawan. Begitu pula dengan Glenda et al.(2017) menyatakan dalam penelitiannya kepemimpinan melayani berpengaruh secara tidak langsung terhadap kinerja yang dimediasi oleh kepuasan kerja.

Laras (2006) menyatakan bahwa ada pengaruh yang signifikan antara kompetensi komunikasi dengan kinerja karyawan. Sementara Mulyadi et al. (2014) menggunakan indikator pengetahuan, motivasi dan keahlian dalam mengukur kompetensi komunikasi yang menemukan bahwa kompetensi komunikasi berpengaruh terhadap kinerja karyawan. Demikian juga Yakub et al. (2015) dalam penelitiannya menyatakan bahwa kemampuan komunikasi berpengaruh signifikan terhadap kinerja karyawan. Hal ini karena kemampuan komunikasi sangat berperan untuk mengetahui cara menempatkan diri dalam situasi yang berbeda-beda dengan rekan kerja. Dimas (2016) menemukan bahwa kepuasan kerja mampu memediasi komunikasi dan kinerja karyawan serta berpengaruh secara positif terhadap kinerja karyawan. Dari berbagai dukungan hasil penelitian tersebut, maka dibangunlah kerangka konseptual penelitianyang dapat dilihat pada gambar berikut ini.

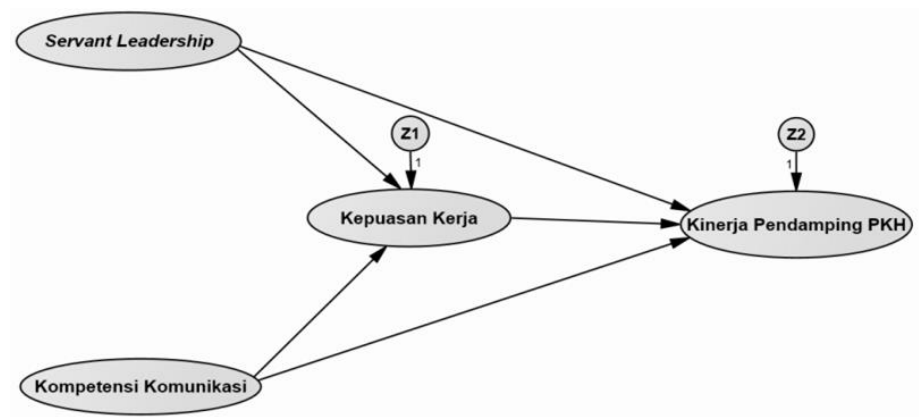

Gambar 1: Kerangka Konseptual

\section{Hipotesis}


Dari latar belakang, kajian pustaka dan kerangka konseptual dapat dirumuskan hipotesis sebagai berikut.

$\mathrm{H}_{1}$ : Servant leadership mempunyai pengaruh yang positif dan signifikan terhadap kepuasan kerja pendamping PKH Aceh Utara.

$\mathrm{H}_{2}$ : Kompetensi komunikasi mempunyai pengaruh yang positif dan signifikan terhadap kepuasan kerja pendamping PKH Aceh Utara.

$\mathrm{H}_{3}$ : Servant leadership mempunyai pengaruh yang positif dan signifikan terhadap kinerja pendamping PKH Aceh Utara.

$\mathrm{H}_{4}$ : Kompetensi komunikasi mempunyai pengaruh yang positif dan signifikan terhadap kinerja pendampingPKH Aceh Utara.

$\mathrm{H}_{5}$ : Kepuasan kerja mempunyai pengaruh yang positif dan signifikan terhadap kinerja pendampingPKH Aceh Utara.

$\mathrm{H}_{6}$ : Kepuasan kerja memediasi pengaruh servant leadership terhadap kinerja pendamping PKH Aceh Utara.

$\mathrm{H}_{7}$ : Kepuasan kerja memediasi pengaruh kompetensi komunikasi terhadap kinerja pendamping PKH Aceh Utara.

\section{Metode Penelitian}

Penelitian ini dilakukan di lingkungan Dinas Sosial Aceh Utara dengan pendamping PKH sebagai objek penelitian. Ruang lingkup penelitian meliputi servant leadership, kompetensi komunikasi, kepuasan kerja dan kinerja karyawan. Populasi dalam penelitian ini meliputi seluruh pendamping PKH Aceh Utara yang berjumlah 166 orang. Penentuan sampel dengan menggunakan metode sensus. Dengan demikian jumlah sampel penelitian ini adalah sama dengan jumlah populasi, yaitu sebanyak 166 responden.

Teknik pengumpulan data yang digunakan dalam penelitian ini adalah dengan menyebarkan kuesioner kepada responden penelitian dan pengukurannya dengan menggunakan Skala Likert (1 untuk bobot terendah dan 5 untuk bobot tertinggi). Sementara, metode analisis data yang akan digunakan dalam penelitian ini adalah Structural Equation Modelling (SEM) yang dioperasikan melalui program Analysis of Moment Structure (AMOS).

\section{Hasil Penelitian dan Pembahasan}




\section{Profil Responden}

Berdasarkan metode penetapan sampel, penulis menyebarkan kuesioner kepada seluruh responden penelitian yang berjumlah 166 orang. Dari 166 responden, 150 responden telah mengembalikan dan mengisinya secara baik dan lengkap. Sedangkan sisanya 16 responden tidak menjawab dikarenakan pada saat penyebaran kuesioner, responden tersebut sedang mendapatkan tugas mengikuti diklat sertifikasi pendamping sosial profesional di BBPKS Regional I Sumatera (Padang). Adapun identitas 150 responden berdasarkan jenis kelamin adalah lebih didominasi oleh laki-laki sebanyak 92 orang $(61,3 \%)$, usia berkisar 31 - 35 tahun sebanyak 72 orang (48\%), jenjang pendidikan Sarjana (S1) sebanyak 133 orang $(88,7 \%)$ dan masa kerja selama 2 tahun sebanyak 78 orang $(52 \%)$.

\section{Uji Asumsi SEM}

Analisis SEM AMOS harus memenuhi kriteria uji asumsi SEM. Data dalam penelitian ini telah mengalami distribusi data yang normal, dimana nilai critical ratio untuk univariate dan multivariate berada dalam rentang $\pm 2,58$. Dalam kajian ini tidak terjadi multikolinieritas antara sesama variabel bebas. Hal ini dapat dilihat dari nilai determinant of sample covariance matrix menjauh dari 0,000.

\section{Ketepatan Model Penelitian}

Full model SEM sebelum modifikasi bertujuan untuk melihat sejauhmana model dasar yang dibentuk dalam penelitian ini memenuhi kriteria goodness of fit index sehingga model dapat menggambarkan fenomena penelitian tanpa adanya modifikasi. Full model dapat dilihat pada gambar berikut ini. 


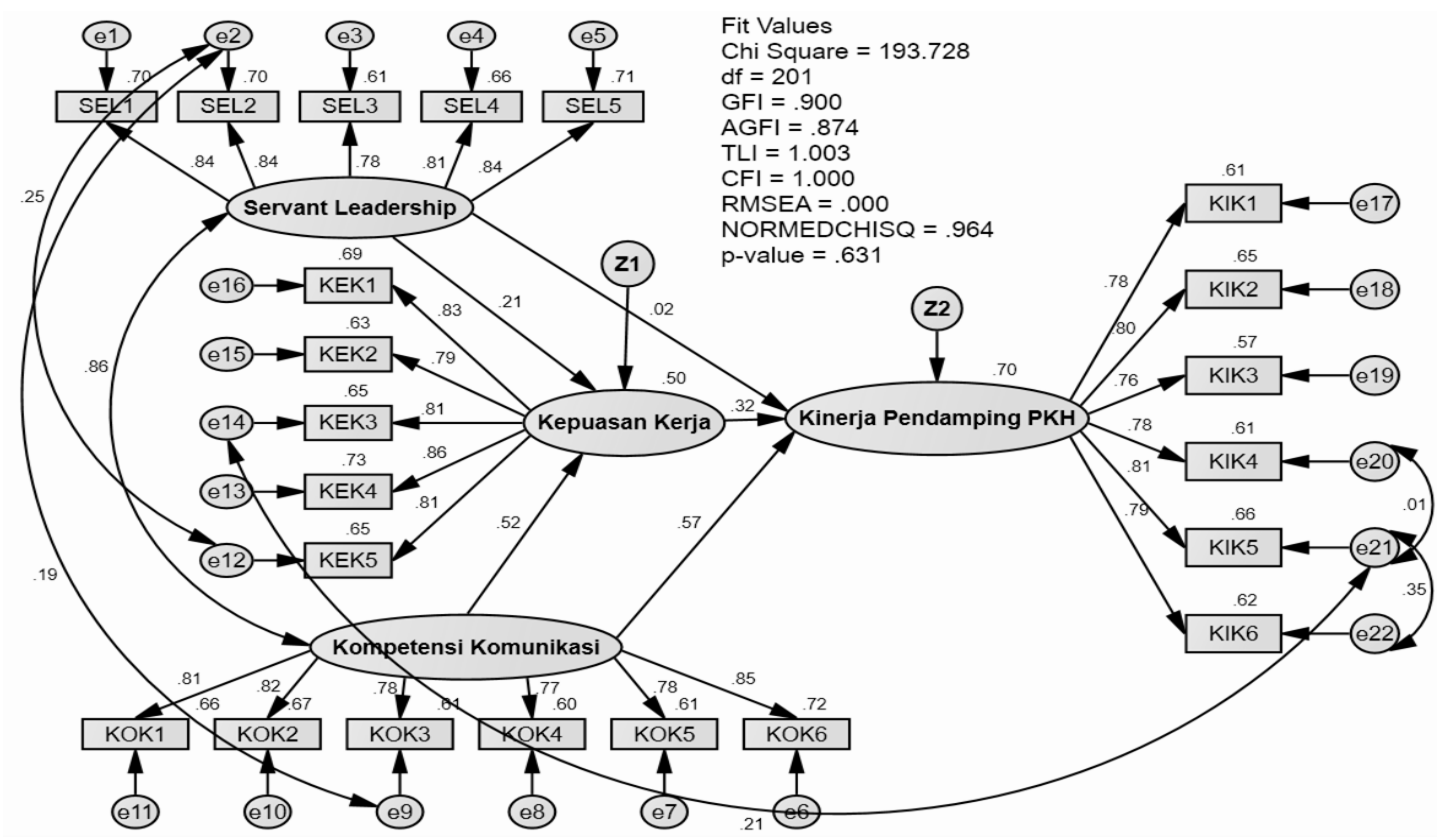

Gambar 2: Model Penelitian

Dari gambar di atas dapat disimpulkan bahwa secara umum semua konstruk yang digunakan untuk membentuk model penelitian ini telah memenuhi kriteria goodness of fit index yang telah ditetapkan seperti nilai Chi-Square nilai GFI, RMSEA,TLI, CFI, CMIN/DF dan P-Value, kecuali nilai AGFI yang masih marginal $(0,874<0,90)$, namun sudah bisa ditolerir karena sudah mendekati baik seperti yang terlihat pada tabel berikut ini.

Tabel 1: Kriteria Goodness Of Fit Full Model

\begin{tabular}{|c|c|c|c|c|}
\hline No & Goodness Of Fit Index & Cut Off Value & Nilai Hasil & Kesimpulan \\
\hline 1 & Chi-square $\left(\mathrm{X}^{2}\right)$ & Diharapkan kecil & 193,728 & Baik \\
\hline 2 & $P$-Value & $\geq 0,05$ & 0,631 & Baik \\
\hline 3 & CMIN/DF & $\leq 2,00$ & 0,964 & Baik \\
\hline 4 & GFI & $\geq 0,90$ & 0,900 & Baik \\
\hline 5 & AGFI & $\geq 0,90$ & 0,874 & Marginal \\
\hline 6 & TLI & $\geq 0,95$ & 1,003 & Baik \\
\hline 7 & CFI & $\geq 0,95$ & 1,000 & Baik \\
\hline 8 & RMSEA & $\leq 0,08$ & 0,000 & Baik \\
\hline
\end{tabular}

Sumber: Data diolah, 2019

\section{Pengujian Hipotesis}

Uji statistik dilakukan dengan mengamati tingkat signifikansi hubungan antar variabel yang ditunjukkan oleh nilai Critical Ratio (C.R). Hubungan yang signifikan 
ditandai dengan nilai Critical Ratio (C.R) yang lebih besar dari 2,58 dan nilai probabilitas (P) lebih kecil dari 0,05 (Ferdinand, 2014). Apabila hasilnya menunjukkan nilai yang memenuhi persyaratan tersebut, maka hipotesis penelitian diterima dan apabila hasilnya menunjukkan nilai yang tidak memenuhi persyaratan tersebut, maka hipotesis yang diajukan ditolak.

Tabel 2: Pengaruh Variabel Eksogen terhadap Variabel Endogen

\begin{tabular}{lllrrrr}
\hline Pengaruh & & & Std.Est. & S.E. & C.R. & Prob. \\
\hline Kepuasan Kerja & $<---$ & KompetensiKomunikasi & 0,517 & 0,159 & 3,248 & 0,001 \\
Kepuasan Kerja & $<---$ & Servant Leadership & 0,213 & 0,159 & 1,343 & 0,179 \\
Kinerja Pendamping & $<---$ & Kepuasan Kerja & 0,316 & 0,086 & 3,494 & $* * *$ \\
Kinerja Pendamping & $<---$ & Servant Leadership & 0,018 & 0,129 & 0,136 & 0,892 \\
Kinerja Pendamping & $<---$ & Kompetensi Komunikasi & 0,567 & 0,144 & 3,744 & $* * *$
\end{tabular}

Sumber: Data diolah, 2019.

Secara terperinci pengajuan hipotesis penelitian akan dibahas secara bertahap sesuai dengan urutan hipotesis yang telah diajukan, yaitu:

\section{Hipotesis 1: Servant leadership mempunyai pengaruh positif dan signifikan terhadap kepuasan kerja pendamping PKH Aceh Utara}

Berdasarkan Tabel 2 di atas dapat dilihat bahwa nilai koefesien estimate regression weight standardized sebesar 0,213, nilai probabilitas (signifikansi) sebesar 0,179 dan nilai Critical Ratio (C.R.) sebesar1,343. Hal ini berarti bahwa servant leadership tidak berpengaruh signifikan terhadap kepuasan kerja pendamping PKH Aceh Utara. Hasil penelitian ini tidak sejalan dengan kebanyakan hasil penelitian yang dilakukan oleh Putri (2014), Pramudya (2017), Saragih (2016), Lisbijanto (2014), Glenda et al. (2017) Fanny (2016), Sukarja dan Machasin (2015) yang menyatakan bahwa servant leadership berpengaruh terhadap kepuasan kerja karyawan. Sehingga perbedaan hasil penelitian ini telah memperkaya kerangka teoritis penelitian. Servant leadership tidak berpengaruh terhadap kepuasan kerja pendamping PKH Aceh Utara karena masih ada hal-hal yang belum sepenuhnya dapat diselesaikan, seperti peralatan kerja yang tidak sebanding dengan jumlah pendamping $\mathrm{PKH}$, penggunaan software yang sering berubah-ubah dan pengawasan yang dilakukan belum dapat mencegah dan meminimalisir kesalahan kerja.

Hipotesis 2: Kompetensi komunikasi mempunyai pengaruh positif dan signifikan terhadap kepuasan kerja pendamping PKH Aceh Utara 
Berdasarkan Tabel 2 di atas dapat dilihat bahwa nilai koefesien estimate regression weight standardized sebesar 0,517 , nilai probabilitas (signifikansi) sebesar $0,001^{* *}$ dan nilai Critical Ratio (C.R.) sebesar 3,248. Hal ini berarti bahwa kompetensi komunikasi berpengaruh positif dan signifikan terhadap kepuasan kerja pendamping PKH Aceh Utara. Hasil penelitian ini mendukung hasil penelitian yang dilakukan oleh Riyadi et al. (2017), Okta (2016), Brahmasari et al. (2008), Sukarja dan Machasin (2015) yang menyatakan bahwa kompetensi komunikasi berpengaruh secara positif dan signifikan terhadap kepuasan kerja karyawan. Hal ini berarti bahwa semakin baik kompetensi komunikasi maka akan semakin meningkatkan pula tingkat kepuasan kerja pendamping PKH Aceh Utara yang telah terbukti secara teoritis dan didukung dari hasil analisis data penelitian.

\section{Hipotesis 3: Servant leadership mempunyai pengaruh positif dan signifikan terhadap kinerja pendamping PKH Aceh Utara}

Berdasarkan Tabel 2, dapat dilihat nilai koefesien estimate regression weight standardized sebesar 0,018, nilai probabilitas (signifikansi) sebesar 0,892 dan nilai Critical Ratio (C.R) sebesar 0,136. Hal ini berarti bahwa servant leadership tidak berpengaruh terhadap kinerja pendamping PKH Aceh Utara. Hasil penelitian ini memperkuat hasil penelitian yang dilakukan oleh Muliadi (2018) dan Gede et al. (2017) yang menyatakan bahwa servant leadership tidak berpengaruh terhadap kinerja karyawan. Sehingga perbedaan hasil penelitian ini telah memperkaya desain kerangka teoritis penelitian tentang arah hubungan antara servant leadership terhadap kinerja karyawan.

Servant leadership tidak berpengaruh secara signifikan terhadap kinerja pendamping PKH Aceh Utara karena masih ada hal-hal yang belum dapat diakomodir secara maksimal, seperti pemenuhan kebutuhan pendamping PKH terkait dengan biaya operasional dan dana sharing belum dapat direalisasikan, masukan dan saran mengenai kendala-kendala yang dihadapi pendamping PKH di lapangan belum sepenuhnya dapat diselesaikan, persoalan teknis yang menghambat pencapaian visi di lapangan juga belum dapat diselesaikan dengan baik dan kurang dapat membaca hal-hal yang dapat menghambat pencapaian visi PKH. Servant leadership dikonsep oleh Greenleaf yang tentunya dipengaruhi oleh nilai-nilai budaya kepemimpinan yang ada di lingkungannya dan belum tentu sesuai jika ditransformasikan dalam nilai-nilai budaya kepemimpinan di Aceh. Bentuk kepemimpinan masyarakat Aceh memiliki kekhasan dan nilai-nilai budaya tersendiri (Wibowo, 2012). 


\section{Hipotesis 4: Kompetensi komunikasi mempunyai pengaruh positif dan signifikan terhadap kinerja pendamping PKH Aceh Utara}

Berdasarkan Tabel 2 di atas dapat dilihat bahwa nilai koefesien estimate regression weight standardized sebesar 0,567 , nilai probabilitas (signifikansi) sebesar $\left(0,000^{* * *}\right)$ dan nilai Critical Ratio (C.R.) sebesar 3,744. Hal ini berarti bahwa kompetensi komunikasi berpengaruh signifikan terhadap kinerja pendamping PKH Aceh Utara. Hasil penelitian ini sejalan dengan hasil penelitian yang dilakukan oleh Akhyar (2018), Filliks (2015), Mulyadi et al. (2014), Laras (2006), Payne (2005), Stevani dan Gita (2016), Setiawan et al. (2014), Rosidah (2004), Laras (2006), Riggio dan Taylor (2000). Hal ini berarti bahwa semakin baik kompetensi komunikasi maka akan semakin meningkatkan kinerja pendamping PKH Aceh Utara. Kompetensi komunikasi memegang peran sentral dalam proses pendampingan program $\mathrm{PKH}$, karena salah satu tugas pendamping $\mathrm{PKH}$ adalah memberikan penyuluhan sosial dengan kompetensi komunikasi merupakan kemampuan mutlak yang harus dimiliki oleh pendamping PKH.

\section{Hipotesis 5: Kepuasan kerja mempunyai pengaruh positif dan signifikan terhadap kinerja pendamping PKH Aceh Utara}

Berdasarkan Tabel 2 di atas dapat dilihat bahwa nilai koefesien estimate regression weight standardized sebesar 0,316 , nilai probabilitas (signifikansi) sebesar $\left(0,000^{* * *}\right)$ dan nilai Critical Ratio (C.R.) sebesar 3,494. Hal ini berarti bahwa kepuasan kerja berpengaruh signifikan terhadap kinerja pendamping PKH Aceh Utara. Hasil penelitian ini sejalan dan sekaligus memperkuat hasil penelitian yang dilakukan oleh Dikyah (2017), (2007) Ahmadi (2009), Putrana (2016) Sutrisno et al. (2017) dan Glenda et al. (2017) yang menyatakan bahwa kepuasan kerja berpengaruh secara positif dan signifikan terhadap kinerja karyawan. Hal ini berarti bahwa semakin tinggi tingkat kepuasan kerja maka kinerja pendamping PKH Aceh Utara akan semakin meningkat yang telah terbukti secara teoritis dan didukung dari hasil analisis data penelitian.

\section{Hipotesis 6: Kepuasan Kerja Memediasi Pengaruh Servant Leadership terhadap Kinerja Pendamping PKH Aceh Utara}

Koefisien jalur a dan c tidak signifikan, yaitu masing-masing nilai signifikansinya sebesar 0,179 dan 0,892. Sedangkan koefisien jalur b signifikan yaitu sebesar 0,000***. Baron dan Kenny (1986) mensyaratkan bahwa sebuah variabel dapat menjadi mediator jika koefisien jalur a, b dan c signifikan. Sehingga dapat disimpulkan bahwa kepuasan kerja tidak memediasi pengaruh servant leadership terhadap kinerja pendamping PKH Aceh Utara. 
Hasil penelitian ini tidak sejalan dengan hasil penelitian yang dilakukan oleh Lisbijanto (2014) dan Glenda et al. (2017) yang menyatakan bahwa kepuasan kerja memediasi pengaruh servant leadership terhadap kinerja karyawan. Sehingga perbedaan hasil penelitian ini memperkaya penelitian.

\section{Hipotesis 7: Kepuasan Kerja Memediasi pengaruh Kompetensi Komunikasi terhadap Kinerja Pendamping PKH Aceh Utara}

Koefisien jalur a, b dan c adalah signifikan sehingga memenuhi persyaratan sebagai variabel mediator sebagaimana ketentuan Baron dan Kenny (1986). Untuk mengetahui apakah hubungan mediasi terjadi secara partial mediation atau secara full mediation dapat dilihat dari signifikansi koefisien jalur c'. Jika koefisien jalur c' signifikan (Sobel test), maka hubungan mediasi terjadi secara partial mediation. Sedangkan jika koefisien jalur c' tidak signifikan, maka hubungan mediasi terjadi secara full mediation. Dari hasil uji Sobel test terlihat bahwa koefisien jalur c' adalah signifikan. Dengan demikian secara parsial kepuasan kerjamemediasi pengaruh kompetensi komunikasi terhadap kinerja pendamping PKH Aceh Utara. Hasil penelitian ini memperkuat hasil penelitian yang dilakukan oleh Dimas (2016), Okta (2015), Gray dan Laidlaw (2002) yang menyatakan bahwa kepuasan kerja memediasi pengaruh kompetensi komunikasi terhadap kinerja karyawan. Sehingga hasil penelitian ini dapat memperkuat teori yang telah ada dalam rangka pengembangan ilmu pengetahuan

\section{Kesimpulan dan Rekomendasi}

\section{Kesimpulan}

Dalam studi ini dapat disimpulkan bahwa servant leadership tidak memiliki pengaruh terhadap kepuasan dan kinerja pendamping PKH Aceh Utara. Sementara kompetensi komunikasi berpengaruh positif dan signifikan terhadap kepuasan dan kinerja pendamping PKH.Variabel kepuasan tidak dapat memediasi hubungan antara servant leadership terhadap kinerja pendamping. Di sisi lain, variabel ini secara parsial memediasi hubungan kompetensi komunikasi terhadap kinerja pendamping PKH.

\section{Rekomendasi}

Kompetensi komunikasi merupakan penggerak utama dalam model kinerja pendamping PKH. Pemerintah seyogyanya memperhatikan variabel ini karena memberikan konstribusi secara menyakinkan dan membantu secara psikologi penerima bantuan PKH. Pelatihan yang mengarah kepada komunikasi yang efektif dan rasa kepedulian perlu dilakukan untuk meningkatkan kompetensi komunikasi. Kepuasan kerja 
juga merupakan faktor penunjang kinerja pendamping PKH. Variabel kepuasan kerja dapat meningkatkan pengawasan kerja dan menciptakan harmonisasi hubungan kerja, serta dapat mengurangi kesalahan kerja. Pemerintah seharusnya memperhatikan variabel ini dengan memberikan bimbingan teknis yang mantap terhadap pendamping $\mathrm{PKH}$.

\section{Saran Bagi Peneliti Lanjutan}

Peneliti lanjutan dapat memperhatikan variabel kompetensi komunikasi dan servant leadership sebagai variabel utama dalam kajian selanjutnya. Menambah variabel lain yang menjadi masalah dalam PKH seperti pengetahuan penerima bantuan terhadap program ini. Seyogyanya responden perlu ditingkatkan agar mengurangi tingkat kebiasan data penelitian.

\section{Ucapan Terima Kasih}

Penulis mengucapkan ribuan terima kasih kepada semua pihak yang terlibat dalam penelitian ini seperti koordinator program, Universitas Malikussaleh dan pemerintah atau kementerian sosial republik Indonesia serta pihak penerbit jurnal yang telah mempublikasikan hasil penelitian ini.

\section{Daftar Referensi}

Al Ahmadi, H., (2009). Factors Affecting Performance of Hospital Nurses in Riyadh Region, Saudi Arabia. International Journal of Health Care Quality Assurance. Volume 22 Nomor 1. Hal. 40 - 54.

Akhyar, Makhlaufi. (2018). Analisis Pengaruh Komunikasi, Motivasi Kerja dan Kepemimpinan terhadap Kinerja Pegawai Dinas Sosial, Pemberdayaan Masyarakat dan Desa Kabupaten Jepara Melalui Intervening Kepuasan Kerja. Tesis Magister Manajemen. Universitas Muria, Kudus.

Bachri, N. (2018). Credibility-Profit Chain in Indonesian Islamic Banking Industry. Indian Journal of Public Health Research \& Development. 9 (12), 1951-1956. https://doi.org/10.5958/0976-5506.2018.02275.1

Bachri, N. (2018). Customer Behavior in Islamic BankingIndustry.Jurnal Visioner \& Strategis. 6(2), 49-57. https://journal.unimal.ac.id/visi/article/view/302

Barbuto,J.E \& Wheeler, D.W. (2006). Scale Development and Construct Clarification of Servant Leadership. (Electronic Version). Group and Organization Management. 31,300-326.

Baron, R. M \& Kenny, D. A. (1986). The Moderator Mediator Variabel Distinction in Sosial Psychological Research: Conceptual, Strategic and Statistical Considerations. Journal of personality and sosial psychology.

Bernardin H.J \& Russel, E.A. (2010). Human Resources Management: An Experiental Approach. Edition 5. Mc Graw Hill Inc, New York

Brahmasari, Ida Ayu dan Suprayetno, Agus. (2008). Pengaruh Motivasi Kerja, Kepemimpinan dan Budaya Organisasi terhadap Kepuasan Kerja Karyawan serta Dampaknya pada Kinerja Perusahaan (Studi Kasus Pada PT. Pei Hai 
Internasional Wiratama Indonesia). Jurnal Manajemen dan Kewirausahaan. Volume 10 Nomor 2.

Dennis, R. (2004). Development of the Servant Leadership Assessment Instrument. Leadership and Organization Development Journal. 5, 18-57.

Dheane, Putri Prastiwi. (2014). Pengaruh Kepemimpinan Melayani (Servant Leadership) dan Karakteristik Pekerjaan (Job Characteristic) terhadap Kepuasan Kerja Karyawan (Job Satisfaction) Studi Pada PT. Cipta Sarina Vidi Yogyakarta. Tesis Magister Manajemen. Universitas Gadjah Mada, Yogyakarta.

Dikyah, M. Salaby Maarif. (2017). Pengaruh Kepuasan Kerja terhadap Kinerja Karyawan dengan Komitmen Afektif sebagai Variabel Permediasi (Studi Pada Karyawan Pengadilan Agama Se Daerah Istimewa Yogyakarta. Tesis Magister Manajemen. Universitas Gadjah Mada, Yogyakarta.

Duwit, Filliks. (2015). Pengaruh Kompetensi Komunikasi, Kecerdasan Emosional, dan Budaya Organisasi terhadap Kinerja Pegawai (Studi Pada Badan Pemberdayaan Masyarakat dan Pemerintahan Kampung Kabupaten Raja Ampat Propinsi Papua Barat). Jurnal EMBA. Volume 3 Nomor 4. Hal. 130 - 141.

Eunike, G. S., Juliana L., \& Gerrit P. (2017).Pengaruh Kepemimpinan Melayani dan Organizational Citizenship Behavior (OCB) terhadap Kinerja dengan Kepuasan Kerja Sebagai Variabel Moderasi (Studi Pada Majelis Jemaat Rehoboth Gereja Protestan Maluku Klasis Pulau Ambon). Jurnal Manis. 1(2), Juli 2017.

Fanny, Sintya Admaja. (2016). Analisa Servant Leadership terhadap Organizational Citizenship Behavior (OCB) melalui Kepuasan Kerja Karyawan di Hotel Bumi Surabaya. Jurnal Universitas Kristen Petra, Surabaya

Ferdinand, Augusty. (2014). Metode Penelitian Manajemen. Semarang: Badan Penerbit Universitas Diponegoro.

. (2014). Struktural Equation Modeling Dalam Penelitian Manajemen, Aplikasi Model Model Rumit Dalam Penelitian Untuk Skripsi, Tesis dan Disertasi Doktor. UNDIP Press, Semarang.

Ghozali, Imam. (2011). Aplikasi Analisis Multivariate Dengan Program IBM SPSS 19. Edisi 5. Badan Penerbit Universitas Diponegoro, Semarang. . (2014). Model Persamaan Struktural Konsep dan Aplikasi dengan Program Amos 22.0. Badan Penerbit Universitas Diponegoro, Semarang.

Gray, Judy dan Laidlaw, Heather. (2002). Part Time Employment and Communication Satisfaction an Australia Retail Organization. Journal of Employee Relations. Volume 24. Nomor 2.

Harwiki, Wiwiek. (2013). Influence of Servant Leadership to Motivation, Organization Culture, Organizational Citizenship Behavior (OCB), and Employees Performance in Outstanding Cooperatives East Java Province, Indonesia. Journal IOSR JBM. 8(5), 50-58.

Hermawati, Istiana. (2012). Evaluasi Program Keluarga Harapan (PKH).B2P3KS Press, Yogyakarta.

Heru Riyadi, Bambang Sapto Utomo dan Anwari Masatip. (2017). Pengaruh Komunikasi, Motivasi Kerja dan Kompetensi terhadap Kepuasan Kerja serta Implikasinya pada Kinerja Dosen pada Perguruan Tinggi Pariwisata Swasta di Jawa Barat. Jurnal THE. Volume 7 Nomor 2. Hal.73

Laras, Tris Ambar Suksesi Edwardin. (2006). Analisis Pengaruh Kompetensi Komunikasi, Kecerdasan Emosional, dan Budaya Organisasi Terhadap Kinerja Karyawan 
(Studi Pada PT Pos Indonesia (Persero) Se Kota Semarang). Tesis Magister Manajemen. Universitas Diponegoro, Semarang.

Lisbijanto, Herry. (2014). Pengaruh Servant Leadership dan Budaya Organisasi Terhadap Kinerja Organisasi Melalui Kepuasan Kerja Pada Koperasi Karyawan di Surabaya. Disertasi Doktor Ilmu Manajemen. Sekolah Tinggi Ilmu Ekonomi Indonesia (STIESIA), Surabaya.

Locander, W.B.F. Hamilton, D. Ladik \& J. Stuart (2002). Developing ALeadership Rich Culture: The Missing Link to Creating A Market FocusedOrganization. Journal of Market Focused Management. 5, 149-163

Lubis, A.R. \& Bachri, N., (2015).The Credibility and Performance of Islamic Banking: Reconceptualizing the Model Service-Profit Chain. $5^{\text {th }}$ Syiah Kuala Universityannual International Conference 2015 (AIC Unsyiah). Banda Aceh, Indonesia.

Luthans, Fred. (2009). Perilaku Organisasi. Edisi 10. Penerbit Andi, Yogyakarta.

Mangkunegara, A.P. (2010). Manajemen Sumber Daya Manusia. Cetakan Ke Enam. PT. Rosda Karya, Jakarta.

Moh. As'ad. (2008). Seri Ilmu Sumber Daya Manusia Psikologi Industri. Remaja Rasda Karya, Yogyakarta.

Nanda, Pramudya. (2017). Pengaruh Kepemimpinan Melayani (Servant Leadership) dan Budaya Organisasional terhadap Kepuasan Kerja Pegawai Pengadilan Negeri Sleman. Tesis Magister Manajemen. Universitas Gadjah Mada, Yogyakarta.

Okta, Dimas Ardiansyah. (2016). Pengaruh Komunikasi Terhadap Kinerja Karyawan Dengan Dimediasi Oleh Kepuasan Kerja (Studi Pada Bagian Produksi Pabrik Kertas PT. Setia Kawan Makmur Sejahtera Tulungagung). Jurnal Bisnis dan Manajemen. 3 (1).

Payne, H. J. (2005). Reconceptualizing Sosial Skills in Organizations: Exploring The Relationship Between Of Leadership And Organizational Studies. 11, 63-77.

Putrana, Yoga. (2016). Pengaruh Kepuasan Kerja dan Komitmen Organisasi terhadap Organizational Citizenship Behavior (OCB) dalam Meningkatkan Kinerja Karyawan pada PT. Gelora Persada Mediatama Semarang. Journal of Management. Volume 2 Nomor 2 Maret 2016.

Rahmat Sukarja dan Machasin. (2015). Pengaruh Kepemimpinan dan Komunikasi terhadap Kepuasan Kerja dan Kinerja Pegawai Dinas Pendidikan Provinsi Riau. Jurnal TEPAK. Volume VII Nomor 2 Mei 2015.

Riggio, R.E., dan Taylor S.J. (2000). Personality and Communication Skills Predictors of Hospice Nurse Performance. Journal Business and Psychology. Volume 15 Nomor 2.

Rivai, Veithzal dan Basri, A.F.M. (2005). Performance Appraisal. PT. Raja Grafindo Persada, Jakarta.

Rivai, Veithzal \& Deddy Mulyadi. (2012). Kepemimpinan dan Perilaku Organisasi. Edisi Tiga. Raja Grafindo Persada, Jakarta

Robbins, S. P \& Judge T. (2015). Perilaku Organisasi. Terjemahan Oleh Diana Angelica. Salemba Empat, Jakarta.

Rowley, R. D. (2002). Communication Competence: The Essence of AligningAction. Retrieved 25 Oktober 2018 from www.algningaction.com

Saragih, Masrul, Indi Djastuti dan Mirwan Surya Perdhana. (2016). Pengaruh Kepemimpinan Pelayan (Servant Leadership) dan Kompetensi terhadap Kepuasan Kerja dalam Meningkatkan Kinerja Pengajar (Studi Pada Lembaga Bimbingan Belajar Ganesha Operation). Jurnal Manajemen Universitas Diponegoro, Semarang 
Sendjaya, S \& Sarros, J. C. (2002). Servant Leadership: Its Origin, Development,and Application in Organizations. Journal of Leadership and OrganizationStudies. Vol.9.

Sendjaya, S. (2015). Personal and Organizational Excellence Through Servant Leadership. Springer International Publishing Switzerland, Australia.

Setiawan Mulyadi, Andi Alimuddin Unde dan Farid Muhammad. (2014). Kompetensi Komunikasi Aparatur Sipil Negara terhadap Kinerja dalam Budaya Organisasi pada Badan Kepegawaian Daerah Kabupaten Biak Numfor. Jurnal KAREBA. Volume 3 No. 4 Oktober - Desember 2014.

Smith, C. (2005). Servant Leadership: The Leadership Theory Of Robert K. Greenleaf. Info 640-MGMT.of info.orgs

Spears, Larry C. (2005). The Understanding and Practice of Servant Leadership. Servant Leadership Research Roundtable. Published By The School Of Global Leadership and Entrepreneurship. Regent University.

Stevani, Melisa dan Theresia Gita Santoso. (2016). Analisis Pengaruh Kemampuan Komunikasi dan Kemampuan Beradaptasi terhadap Kinerja Karyawan di Celebrity Fitness Galaxy Mall. Jurnal E-Komunikasi. Volume 2 Nomor 3. Universitas Kristen Petra, Surabaya.

Suardi Y., Rudi G.,\& Jufri H. (2015).Pengaruh Kemampuan Komunikasi dan Kecerdasan Emosional TerhadapKinerja Karyawan Pada PT. Perkebunan Nusantara I (Persero) Aceh. Jurnal SAINTIKOM. 14 (3), September 2015.

Sulistiyani, Rosidah T Ambar. (2003). Manajemen Personalia. Edisi Keempat. Ghalia Indonesia, Jakarta.

Sutrisno, Andi Tri Haryono dan Moch Mukeri Warso. (2017). Pengaruh Kepuasan Kerja dan Komitmen Organisasi terhadap Kinerja Karyawan melalui Organizational Citizenship Behavior sebagai Variabel Intervening (Studi Kasus Karyawan PT. Fumira Semarang). Jurnal Manajemen Universitas Pandanaran, Semarang

Syafei, Rachmat. (2000). Al Hadist : Aqidah, Akhlak, Sosial dan Hukum. Pustaka Setia, Bandung.

Wibowo, Agus Budi. (2012). Sistem Kepemimpinan pada Etnis Aceh di Aceh (System Leadership in Acehnese). Jurnal SUWA. Nomor 14 Tahun 2012. 